To the Editors:

\title{
Reducing abortions is a public health issue
}

We read with interest the letter (1) written in response to our article with the above heading in the Ceylon Medical Journal (2). Jayasuriya has stated the pro-life view and claims that human life starts at conception, and that emergency contraception (EC) which prevents implantation is tantamount to an abortion. The recent judgment by the United Kingdom High Court (3) on EC is here pertinent.

In this case the Society for the Protection of Unborn Children claimed that EC was a method of early abortion. They further suggested that supply of EC was a criminal offence under the 1861 Offences Against the Person Act, which prohibits the supply of any "poison or any other noxious thing" with intent to cause miscarriage.

The UK high court rejecting these claims argued: "Up until the attachment stage, the embryo is not attached in any way to the woman herself" and added: "Current medical definitions support the view that pregnancy begins once the blastocyst has implanted in the endometrium and, more particularly, that miscarriage is the termination of such a post-implantation pregnancy".

In terms of how EC works, the judge pointed out that once an embryo had implanted, or had begun to implant "the morning after pill cannot act to cause it to de-implant".

\section{References}

1. Jayasuriya L. Reducing abortions is a public health issue. Ceylon Medical Journal 2001; 46: 163.

2. Gunasekera PC, Wijesinghe PS. Reducing abortions is a public health issue. Ceylon Medical Journal 2001; 46: 41-4.

3. Mayer S. Court rules that emergency contraception is lawful. British Medical Journal 2002; 324: 995.

PS Wijesinghe, Senior Lecturer, Department of Obstetrics and Gynaecology, Faculty of Medicine, Ragama. (Tel: 0717 39685, email: pswijesinghe@1ycos.com), and Prasanna Gunasekera, Specialist, Reproductive Health Services, UNFPA Country Technical Service Team for South and West Asia, P O Box 5940, Kathmandu, Nepal (Tel: 977 1523880, Fax: 9771 527257, email: pgunasekera@unfpa.org.np). 